\title{
Os momentos da teoria das situações didáticas no ensino de matemática
}

\section{The moments of the theory of didactic situations in the teaching of mathematics}

\author{
Francisco Wagner Soares Oliveira \\ Instituto Federal de Educação, Ciência e Tecnologia do Ceará (IFCE), Campus Fortaleza \\ Programa de Pós-Graduação em Ensino de Ciências e Matemática, Fortaleza, CE, Brasil \\ franciscowagner2007@gmail.com
}

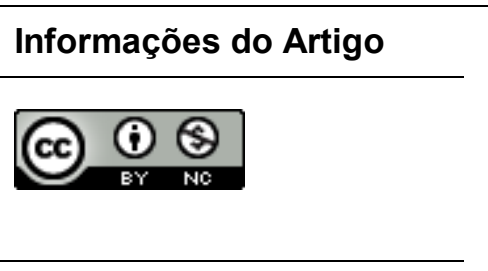

Histórico do Artigo

Submissão: 27 de abril de 2018.

Aceite: 19 de julho de 2018.

Palavras-chave

Ensino de Matemática

Metodologias de Ensino

Teoria das Situações Didáticas

\section{Resumo}

O presente artigo se desenvolveu sob a perspectiva de que a Teoria das Situações Didáticas pode favorecer o trabalho do professor no sentido de propor, acompanhar e caracterizar os momentos de uma atividade em sala. Estabelecemos como objetivo para a pesquisa compreender a utilização da teoria das situações didáticas no ensino de matemática. Para tanto, fizemos uso dos pressupostos de uma pesquisa bibliográfica. Assim, verificamos que compõem a Teoria da Situações Didáticas os momentos dialéticos de devolução, ação, formulação, validação e institucionalização. Sobre o momento de devolução, notamos que mesmo não estando presente na redação das situações de ensino de um determinado estudo, deve ter sido pensado e executado inicialmente pelo professor, pois é ele que, de certa forma, assegura o empenho dos alunos para o desenvolvimento da atividade. Sobre o momento de ação, entendemos que nele os alunos precisam ser possibilitados compreender o problema, visto que devem fazer escolhas e tomar decisões por ações sobre o milieu. Quanto ao de formulação, notamos que ele está associado à troca de informações entre alunos no sentido de elaborar uma comunicação linguística para apresentar seus julgamentos. Por sua vez, quanto ao de validação entendemos que funciona como uma espécie de debate, em que os alunos buscam expor e defender o modelo/solução por eles elaborado para a situação proposta. Por fim, do momento de institucionalização entendemos que o professor tem que assumir o andamento da situação, no sentido de checar o que os alunos compreenderam para buscar institucionalizar os conceitos propostos na atividade.

\section{Abstract}

The present article was developed from the perspective that the Theory of Didactic Situations can favor the work of the teacher in the sense of proposing, accompanying and characterizing the moments of an activity in the classroom. We established as objective for the research to understand the use of the Theory of Didactic Situations in the teaching of mathematics. For this, we made use of the presuppositions of a bibliographical research. Thus, we found that the dialectic moments of devolution, action, formulation, validation and institutionalization make up the Theory of Didactic Situations. About the devolution moment, we noticed that even though it is not present in the writing of the teaching situations of a given study, it must have been thought and executed initially by the teacher, because is this that, in a certain way, ensures the commitment of the students to the activity development. About the action moment, we understood that students need to be able to understand the problem, since they must make choices and decisions for actions on the milieu. About the formulation, we noticed that it is associated with the exchange of information among students in order to elaborate a linguistic communication to present their judgments. On the other hand, in terms of validation we understood that it works as a kind of debate, in which students seek to expose and defend the model / solution they have developed for the proposed situation. Finally, from the institutionalization moment we concluded that the teacher has to assume the progress of the 
situation, in order to check what the students understood to seek to institutionalize the concepts proposed in the activity.

\section{Introdução}

O ensino da matemática exige cada vez mais que o professor consiga prever algumas situações que podem emergir em sala de aula, a fim de ter aporte suficiente para lidar com elas e possibilitar uma aprendizagem significativa a seus alunos.

O presente estudo tem a Teoria das Situações Didáticas (TSD) como metodologia, pois Brousseau (2008) entende que tal teoria pode auxiliar o professor na medida que supre parte dos anseios que o processo de ensinar requer.

Sob tal perspectiva, sustentamos a necessidade de tecermos informações sobre a utilização da TSD em sala, pois acreditamos que, de posse de tais considerações, o professor de matemática terá expandida a oportunidade de compreender a metodologia de ensino utilizada por professores na França.

Algumas pesquisas nacionais já têm se desenvolvido à luz da utilização da TSD como metodologia de ensino no trabalho com a matemática. Como exemplo destas, destacamos os estudos de Souza e Lima (2014), Silva (2015), Alves (2016), Barbosa (2016) e Santos (2017). Tais trabalhos buscam utilizar a TSD como forma de favorecer o ensino e/ou o trabalho de determinados conteúdos em sala. Partindo desta suposta possibilidade de favorecimento, elencamos a seguinte questão norteadora para estudo: como a TSD pode ser aplicada pelo professor de matemática para o desenvolvimento de suas atividades em sala de aula?

O objetivo principal deste estudo é compreender a utilização da teoria das situações didáticas no ensino da matemática. Para tanto, de forma a alcançar essa intenção, utilizamos a pesquisa bibliográfica como metodologia de estudo, sendo esta desenvolvida a partir da análise de trabalhos já publicados na literatura que versam a respeito do ensino de matemática.

Os embasamentos apresentados a seguir estão ancorados nas considerações apresentadas por: Almouloud (2007), Brousseau (2008), Teixeira e Passos (2013), Saito (2017), Alves (2017) e Santos (2017).

\section{Referêncial Teórico}

A metodologia de ensino teve seu desenvolvimento a partir dos estudos do pesquisador francês Guy Brousseau na década de noventa. Essa teoria tem por objetivo:

[...] caracterizar um processo de aprendizagem por uma série de situações reprodutíveis, conduzindo frequentemente à modificação de um conjunto de comportamentos dos alunos. Essa modificação é característica da aquisição de um determinado conjunto de conhecimentos, da ocorrência de uma aprendizagem significativa. (ALMOULUOD, 2007, p. 31). 
Mediante experiências com o ensino de matemática, entendemos que tal caracterização certamente é uma tarefa difícil, isso porque o processo de aprendizagem diz respeito principalmente às competências do aluno. No entanto, o êxito na modelagem desse processo pode possivelmente nos ajudar a rever e propor nossas práticas.

Nessa perspectiva, quanto à caracterização do processo de aprendizagem em situações de ensino, Brousseau (2008) destaca o jogo de interações entre o professor, o saber e o aluno e do aluno com o Milieu (meio), que podem emergir e que devem ser levados em conta durante as atividades (Figura 1).

Figura 1 - Esquema didático das relações entre professor-saber-aluno-meio.

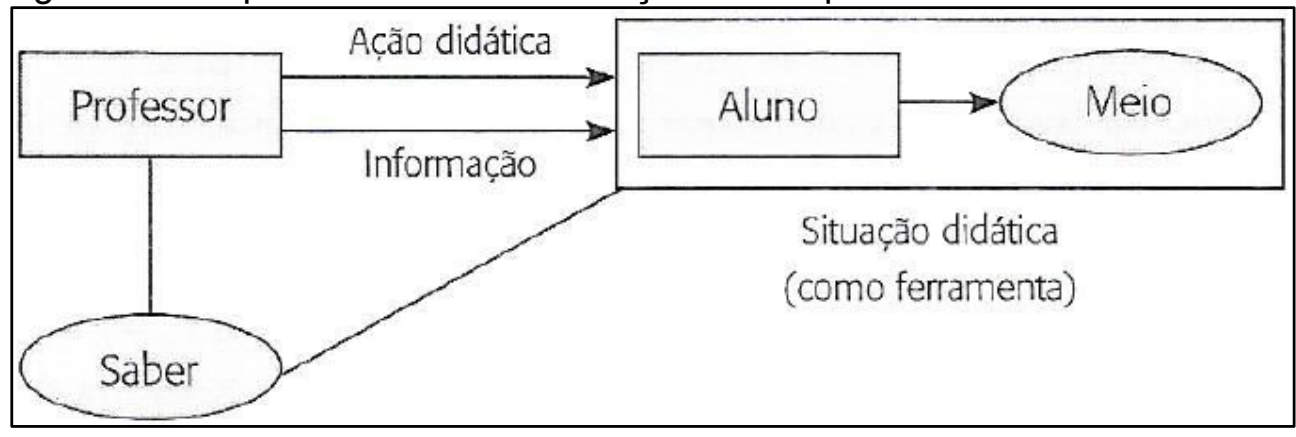

Fonte: Brousseau (2008, p. 54).

Conforme observado, a TSD tem como uma de suas finalidades orientar o professor a desenvolver situações reproduzíveis de ensino que podem proporcionar ao aluno uma aprendizagem mais significativa. Sobre a metodologia de ensino, cabe observar a seguinte explicação:

Consideremos um dispositivo criado por alguém que queira ensinar um conhecimento ou controlar sua aquisição. Esse dispositivo abrange um meio material - as peças de um jogo, um desafio, um problema, inclusive um exercício, fichas etc. - e as regras de interação com esse dispositivo, ou seja, o jogo propriamente dito. Contudo, somente o funcionamento e o real desenvolvimento do dispositivo, as partidas de fato jogadas, a resolução do problema etc. Podem produzir um efeito de ensino. Portanto, deve-se incluir o estudo da evolução da situação, visto pressupormos que a aprendizagem é alcançada pela adaptação do sujeito, que assimila o meio criado por essa situação, independentemente de qualquer intervenção do professor ao longo do processo. Os conhecimentos se manifestam essencialmente como instrumentos de controle das situações. (BROUSSEAU, 2008, p. 22).

Quanto ao conjunto de situações que caracterizam o processo de ensino e aprendizagem, vale destacar que estas podem ser entendidas individualmente como didáticas ou adidáticas. Pelo observado em Teixeira e Passos (2013), uma situação didática, com vistas ao ensino de um determinado conhecimento, pode ser definida, dentre outros fatores, como sendo um jogo de relações entre o aluno, o milieu (meio) e o professor, já uma situação adidática seria definida como parte de uma situação didática, tendo como característica intenções didáticas, porém, estas não são reveladas ao aluno durante seu desenvolvimento. 
No que diz respeito às situações adidáticas, cabe observar ainda que um conjunto dessas pode ser chamado de situação fundamental que "[...] constitui um grupo restrito de situações adidáticas cuja noção a ensinar é a resposta considerada a mais adequada/indicada, situações que permitem introduzir os conhecimentos em sala de aula numa epistemologia propriamente científica" (ALMOULOUD, 2007, p. 34).

Nessa perspectiva, vale destacar ainda a noção de uma situação de devolução, a qual pode ser "[...] definida como o ato pelo qual o professor faz o aluno aceitar a responsabilidade de uma situação de aprendizagem (adidática) ou de um problema aceitando as consequências dessa transferência" (ALMOULOUD, 2007, p. 35).

Nesse sentido, mais especificamente quanto a modelagem da teoria das situações, Almouloud (2007) indica que, para o desenvolvimento da TSD em sala, o professor precisa ter em mente 04 (quatro) momentos dominantes, sendo estes o de ação, o de formulação, o de validação e o de institucionalização. Inicialmente, em Brousseau (2008), os pesquisadores acreditavam que os momentos de ação, formulação e validação já caracterizavam todos os tipos de situações possíveis e necessárias ao se trabalhar em sala.

Contudo, posteriormente, em observação ao desenvolvimento das situações de ensino em sala, começaram a notar a necessidade de se incorporar à teoria das situações, além das três fazes adidáticas já contempladas, um outro momento, o qual desse um maior protagonismo à ação do professor, visto verificarem que, após os momentos ação, formulação e de validação, ainda se necessitava checar o entendimento do aluno e guiá-lo no sentido de institucionalizar o conhecimento posto na atividade. Esse momento recebe o nome de institucionalização.

Ademais, quanto a tais momentos, vale destacar que a ação tem, dentre outras características, possibilitar ao aluno, de posse de conhecimento prévio, interagir com o meio para a busca de soluções. Já o momento posterior, nomeado de formulação, é caracterizado, dentre outros pontos, por ser uma fase em que se necessita de uma participação por parte dos estudantes ainda maior do que a já realizada no momento anterior, no sentido de estabelecer com o grupo uma troca de informações que lhes permita formular uma comunicação linguística para expor seus achados (BROUSSEAU, 2008).

A validação é a fase em que o aluno passa a validar ou não as suas próprias considerações apresentadas quanto ao problema apresentado inicialmente na situação de ensino. Por fim tem-se a fase de institucionalização, caracterizada, dentre outros aspectos, por ser o momento em que o professor expõe suas intenções quanto ao problema proposto na atividade. (BROUSSEAU, 2008).

Quanto a estes momentos que constituem a TSD como uma metodologia de ensino, destacamos o que fora observado em Teixeira e Passos (2013), em que indicam que ela também pode ser incorporada em uma metodologia de pesquisa. Como exemplo, temos o caso da Engenharia Didática, a qual pode apropriar-se da TSD a fim de elaborar e controlar as situações de ensino, validando ou não algumas questões levantadas por essa metodologia de pesquisa. 
Como exemplo, temos o estudo de Santos (2017), que se desenvolveu à luz da Engenharia Didática e fez uso da TSD, e o de Saito (2017), que também fez uso de tal metodologia de ensino para o desenvolvimento de uma situação-problema. De tais estudos foi possível entendermos que a TSD também pode ser utilizada como um instrumento de investigação, visto que sua elaboração exige um estudo inicial e que, por vezes, tem como intenção controlar e validar a atividade proposta.

De posse dessas considerações, é possível compreender que a TSD como metodologia de ensino caracteriza-se como:

[...] um modelo teórico, segundo o qual, considerando o ensino como projeto e ação social em que o aprendiz se apropria de um saber constituído ou em constituição, a didática da matemática se transforma numa ciência das condições de transmissão e apropriação dos conhecimentos matemáticos (TEIXEIRA; PASSOS, 2013, p. 163).

É sob tal entendimento quanto à TSD que reforçamos a necessidade de nosso estudo frente ao processo de ensino-aprendizagem de matemática, pois somente com a compreensão das fases da TSD, o professor se apropriará de tal metodologia.

De forma a alcançar o objetivo da pesquisa e à luz de nossa pergunta norteadora, passamos a observar os estudos de Alves (2016) e Santos (2017), em que trabalharam sob os pressupostos da TSD no ensino da matemática.

\section{Metodologia}

Como já apresentado anteriormente, nosso estudo se desenvolveu com o objetivo principal de compreender a utilização da teoria das situações didáticas no ensino da matemática e sob a perspectiva de uma pesquisa bibliográfica, a qual, segundo MARCONI e LAKATOS (2003), possibilita, por meio do enfoque dado ao trabalho, examinar determinadas questões do objeto de estudo, de tal forma a se chegar em conclusões inovadoras.

MARCONI e LAKATOS (2003) destacam como fases da pesquisa bibliográfica as etapas de: escolha do tema, elaboração do plano de trabalho, identificação, localização, compilação, fichamento, análise, interpretação e de redação do texto. Em conclusão a esses momentos, descrevemos a seguir como foram feitas as considerações da fase de análise e interpretação dos dados apresentada posteriormente na seção resultado e discussão.

Certos autores como Souza e Lima (2014), Silva (2015), Alves (2016), Barbosa (2016) e Santos (2017), têm como um de seus objetivos validar ou não atividades por eles elaboradas. Estes são exemplos de trabalhos que podem ser observados para compreender as situações de ensino que compõem a TSD. Nessa perspectiva, passamos a analisar as atividades de ensino de duas destas pesquisas.

A opção pelo número reduzido de trabalhos pode favorecer a interpretação indicada por MARCONI e LAKATOS (2003), visto que, dessa forma, poderemos nos debruçar com maior dedicação a cada estudo e, assim, possivelmente, extrair argumentos que possibilitem um entendimento mais refinado quanto às situações dialéticas de ensino que compõem a TSD. 
Nessa perspectiva, os estudos escolhidos desenvolveram-se no âmbito da formação inicial dos professores. Segundo Mello (2000) ela ser uma das prioridades da Educação brasileira no presente século. Os estudos elencados para análise foram os de Santos (2017) e o de Alves (2016).

Na dissertação de Santos (2017), o autor partiu dos pressupostos da Engenharia Didática como metodologia de pesquisa. Como forma de levar o estudo inicial à sala de aula, fez uso das atividades de ensino propostas na TSD, pois entende que essa teoria pode o auxiliar na análise e validação das informações observadas. A aplicação de seu estudo se desenvolveu com estudantes de graduação em matemática, em quatro situações problemas de ensino.

Alves (2016), em seu artigo, propõe um trabalho com estudantes de matemática em formação inicial, o qual foi ancorado nos momentos que constituem a TSD. A atividade foi realizada em apenas uma situação didática e em um único dia. Entendemos que, com ela, o docente da disciplina de cálculo III espera estabelecer um modelo em que os professores possam se apropriar para controlar e favorecer o ensino dos temas de funções abordados.

De forma a alcançar nosso objetivo principal, passamos a buscar interpretar por meio de uma análise sobre as situações dialéticas de ensino, que se fizeram presentes nos referidos estudos, levando em consideração as informações apresentadas no referencial teórico.

\section{Resultados e Discussão}

Para Santos (2017), a utilização do método permite ao professor instigar seus alunos a formularem definições sobre os temas abordados na situação de ensino. O referido autor utiliza a TSD, dentre outras finalidades, com o objetivo de validar ou não as situações de ensino, elaboradas a partir do estudo com a engenharia didática, sobre conceitos referentes ao estudo de sequências recursivas lineares.

Ainda nesse sentido, segundo Alves (2016), a TSD tem como uma de suas facetas nos proporcionar realizar a descrição das situações de ensino, já que ela possibilita ao professor visualizar separadamente os momentos de uma aula. Quanto ao estudo desenvolvido pelo referido autor, notamos que a proposta de atividade desenvolvida visa trabalhar o ensino de funções com vistas a decidir e classificar a natureza dos pontos extremantes de duas funções, caso existam.

De uma análise inicial acerca destes trabalhos, elaboramos a seguinte Tabela 1 como forma de apresentar quais situações da TSD foram de fato comtempladas nos referidos estudos. Nela as marcações com o símbolo $(x)$ indicam o desenvolvimento do momento em questão e as com o (-) que tal situação não foi descrita. 
Tabela 1 - Momentos da TSD identificados na descrição das atividades de ensino realizadas nas pesquisas em análise.

\begin{tabular}{l|c|c|c|c|c}
\hline \multirow{2}{*}{ Pesquisa } & \multicolumn{5}{|c}{ Momentos da Teoria das Situções Didáticas } \\
\cline { 2 - 6 } & $\begin{array}{c}\text { Situação de } \\
\text { devolução }\end{array}$ & $\begin{array}{c}\text { Situação de } \\
\text { ação }\end{array}$ & $\begin{array}{c}\text { Situação de } \\
\text { formulação }\end{array}$ & $\begin{array}{c}\text { Situação de } \\
\text { validação }\end{array}$ & $\begin{array}{c}\text { Situação de } \\
\text { institucionalização }\end{array}$ \\
\hline Santos (2017) & - & $\mathrm{x}$ & $\mathrm{x}$ & $\mathrm{x}$ & $\mathrm{x}$ \\
\hline Alves (2016) & - & $\mathrm{x}$ & $\mathrm{x}$ & $\mathrm{x}$ & $\mathrm{x}$ \\
\hline
\end{tabular}

Fonte: Elaboração do autor.

Pelo apresentado na Tabela 1, chamou atenção o fato que Santos (2017), assim como dá destaque às situações de ação, formulação, validação e institucionalização mencionando as realizações e discussões previstas em cada uma delas, o referido autor, mesmo tendo apresentado em seu referencial teórico a situação de devolução, como uma das fases da TSD, não destaca tal momento na descrição das atividades.

Alves (2016), também, ao descrever a atividade desenvolvida em seu trabalho, não apresenta o momento de devolução dentre as tipologias das situações desenvolvidas em seu estudo. O que até certo ponto se justifica, já que em seu referencial teórico não o menciona como uma das etapas da TSD.

No estudo de Santos (2017), com base em suas descrições iniciais, apresentadas antes de descrever o momento de ação de cada atividade, e nas considerações teóricas de Almouloud (2007) apresentadas anteriormente quanto à situação de devolução, notamos a presença de algumas características que indicam a realização de tal momento.

Uma das características refere-se ao fato de como o autor descreve a proposta da atividade no sentido de informar a importância dela para a constituição e andamento de sua pesquisa, posteriormente orientou os estudantes a interagir com os demais alunos durante a situação e por fim menciona ainda que realizou uma leitura compartilhada da atividade com os alunos.

Nessa perspectiva, compreendemos que Santos (2017) fez, possivelmente, uso de uma situação de devolução no desenvolvimento de suas atividades. Embora Alves (2007) não tenha apresentado na descrição o momento da devolução apresentada por Almouloud (2007), acreditamos que o tenha realizado, pois sua exclusão poderia possivelmente comprometer o andamento da atividade, visto que é nele em que se busca firmar o comprometimento e a responsabilidade dos alunos para a evolução dos momentos que constituem a atividade.

No que diz respeito ao momento de ação, ambos apresentaram a descrição de tal situação em seu trabalho. Elucidamos, inicialmente, o estudo de Alves (2016), em que destaca que suas interferências se limitaram a estimular os estudantes a debater em grupo sobre o problema proposto pela atividade, solicitando-os que o explorassem e que o foco foi apresentar a eles informações que Ihes possibilitassem a tomada de decisões para a resolução da situação proposta.

Por sua vez, Santos (2017), em sua primeira atividade, descreve, ao mesmo tempo, os momentos de ação e de formulação, nas demais atividades o referido autor já as apresenta 
separadamente. Em suma, cabe destacar que, durante os momentos de ação descritos pelo pesquisador, entendemos que ele procurou expor o problema ao aluno até que sua compreensão permitisse a tomada de decisões.

Chamou-nos a atenção observar a forma como Santos (2017) descreveu sua primeira atividade, visto ter apresentando a situação de ação junto com a de formulação. Tal feito nos fez levantar a hipótese de que não parece ser uma tarefa simples, tanto para o pesquisador como para os alunos (sujeitos da pesquisa), compreender os instantes de conexão ou de ruptura entre as fases da TSD.

Conforme observado na descrição, destacamos a existência de uma proximidade das ações realizadas em tais estudos com as características do momento de ação suscitadas em nosso referencial, com base em Brousseau (2008).

Quanto à situação de formulação desenvolvida nos dois estudos, destacamos inicialmente o observado em Alves (2016). O autor menciona que sugeriu ao grupo a exploração do problema que abordava as características de determinadas funções no Software GeoGebra e a observação do comportamento delas a partir da utilização do controle deslizante presente em tal recurso, tendo como intenção permitir que os estudantes investigassem e levantassem inferências quanto ao problema proposto.

Em Santos (2017), assim como observado em Alves (2016), podemos notar uma certa aproximação com a característica apresentada quanto ao momento de formulação destacado anteriormente pelo entendimento de Brousseau (2008). Isso porque Santos (2017) descreve que, durante essas situações, os estudantes em grupo conseguiram obter alguns resultados, os quais os permitiram formular algumas possíveis soluções para atividade proposta.

A situação de validação, observada na tabela 1, foi contemplada nos dois estudos. Alves (2016), sobre seu estudo, descreve que, em tal momento, os alunos, a partir de conjecturas elaboradas e confrontadas por eles, passaram a ser estimulados e auxiliados na realização de uma investigação que os possibilitasse uma determinação de possíveis definições ou conceitos contemplados no problema.

Em Santos (2017), podemos observar que, durante os momentos de validação, os estudantes foram instigados a, com base em suas formulações elaboradas em situações anteriores, caracterizar matematicamente um modelo para o problema em questão. Tendo, para tanto, a oportunidade de realizarem uma prova (demonstração) a partir de conhecimentos prévios.

Pelo observado nos referidos estudos, quanto aos momentos de validação, entendemos que ambas as considerações vão ao encontro de Brousseau (2008) no que se refere a tal situação de ensino.

Como última situação da TSD, destacada na Tabela 1, apresentada anteriormente, a etapa de institucionalização foi citada/comentada nas duas pesquisas em análise. Em Alves (2016), 
podemos verificar que, durante esse momento, de forma a favorecer a compreensão dos alunos, o professor enuncia e demostra o teorema abordado.

Santos (2017), durante a descrição da aplicação das atividades, informa que a situação de institucionalização será retomada apenas durante a última etapa da engenharia didática (análise a posteriori e validação), fazendo dessa forma uma associação entre tal metodologia de pesquisa com a TSD como metodologia de ensino.

Pela descrição da análise a posteriori e validação do estudo realizado (últimos momentos da engenharia didática), entendemos que durante os momentos de institucionalização, tendo em vista o estabelecimento ou formulação de definições, é deixado claro para os alunos suas intenções de ensino com a aplicação da atividade e, ainda, indica as propriedades matemáticas formais trabalhadas.

Dessa forma, vale destacar, quanto ao momento de institucionalização observado, que ambas as pesquisas analisadas se desenvolvem sobre os pressupostos de tal metodologia de ensino da forma como indicado por Brousseau (2008).

Mediante nossas observações nos referidos estudos mencionados acima, no que diz respeito à utilização da TSD no ensino de matemática, somadas as considerações teóricas de Almouloud (2007), Brousseau (2008) e de Teixeira e Passos (2013), permitiu-nos compreender que a TSD, aplicada a uma situação de ensino, assim como apresenta Almouloud (2007), se divide nos momentos dominantes de ação, formulação, validação e institucionalização.

Do observado, compreendemos portanto, que o momento de ação pode ser caracterizado como uma fase puramente experimental da situação, em que o aluno deverá, a partir da observação e imersão no milieu e na atividade proposta, orientar suas ações por meio da tomada de decisões e ajuste sobre elas. Dessa forma, o entendimento do aluno ocorreria como uma espécie de aprendizagem por adaptação, a qual ocorre sem a intervenção direta do professor, caracterizandose, dessa forma, como uma situação adidática.

O momento de formulação pode ser compreendido como uma situação em que ocorre muita troca de informações entre os alunos e o meio organizado pelo professor para a situação de ensino. Essa interação deve ocorrer para que os alunos possam elaborar e rever sua comunicação linguística, a fim de expressar resultados compreensíveis ao restante do grupo.

Sobre o momento de validação, etapa em que os estudantes tentam apresentar os argumentos formulados, foram utilizados mecanismos de prova para convencer os demais da solução encontrada frente a situação proposta. Assim, seu modelo de solução para a situação proposta é submetido ao julgamento dos demais, momento que pode leva-lo, a partir das considerações do grupo, a refletir tanto sobre sua proposta de solução como também sobre suas escolhas realizadas em fases anteriores.

Por fim, compreendemos que o momento de institucionalização é a fase em que o professor busca formalizar matematicamente o conteúdo trabalhado na situação de ensino. Para tanto, ele 
deve assumir o protagonismo da atividade, no sentido de observar o que os estudantes conseguiram assimilar para, dessa forma, tentar assegurar que os alunos de fato entendam os conceitos matemáticos incorporados na atividade.

\section{Considerações Finais}

Mediante o observado em nosso estudo, entendemos que a TSD é uma metodologia de ensino que se caracteriza pelo jogo de interações que podem emergir entre os aprendizes, o saber e o meio, o qual, por sua vez, deve ser pensado e elaborado conforme as intenções didáticas do professor previstas para a atividade.

Nesse sentido, destacamos que a TSD pode auxiliar o professor na elaboração e na previsão dos momentos das situações de ensino, bem como os alunos na compreensão do conteúdo proposto para a aula, já que o planejamento da atividade, por parte do professor, deve levar em conta a necessidade de favorecer uma compreensão significativa do aluno.

Diante do exposto, compreendemos que as fases da TSD são caracterizadas pelos momentos de devolução, ação, formulação, validação e, por fim, o de institucionalização. Contudo, cabe observar ainda que a primeira situação destacada pode não estar descrita na elaboração do texto final de uma pesquisa realizada sobre os pressupostos da TSD.

Contudo, entendemos que, para a utilização da Teoria das Situações, o professor deve, inicialmente, apropriar-se teoricamente e didaticamente do que caracteriza cada um desses momentos que compõem a incorporação metodológica da TSD em situações na sala de aula, pois, dessa forma, possivelmente, terá mais embasamentos para propor suas atividades de ensino.

Nessa perspectiva, por termos elencado considerações de cunho teórico e até certo ponto didáticos sobre a TSD por meio do estudo bibliográfico, acreditamos na relevância de nosso estudo frente ao ensino de matemática, já que buscamos apresentar nosso entendimento quanto as fases de devolução, ação, formulação, validação e institucionalização que compõem uma situação de ensino elaborada sob os pressupostos da TSD. Ademais, entendemos que ela se mostra um tanto quanto valiosa no processo da função de ensinar do professor, visto possibilitar a ele controlar e validar a atividade de ensino.

\section{Referências}

ALMOULOUD, S. A. Fundamentos da didática da matemática. 3. ed. Curitiba: UFPR, 2007.

ALVES, F. R. V. Teoria das situações didáticas (TSD): sobre o ensino de pontos extremantes de funções com arrimo da tecnologia. Revista Eletrônica Sala de Aula em Foco, Espírito Santo, v. 5, n. 2, p.59-68, 2016.

BARBOSA, M. J. F. Teorema de Tales: uma abordagem por do meio da Teoria das Situações Didáticas. In: Encontro Brasileiro de Estudantes de Pós-Graduação em Educação Matemática (EBRAPEM), XX, 2016, Curitiba, GD2 Educação Matemática nos anos finais do Ensino Fundamental, Curitiba, 2016. 
BROUSSEAU, G. Introdução ao estudo das situações didáticas: conteúdos e métodos de ensino. Trad.: Camila Bogéa. 1. ed. São Paulo: Ática, 2008.

MARCONI, M. de A.; LAKATOS, E. M. Fundamentos de metodologia científica. 5. ed. São Paulo: Atlas, 2003.

MELLO, G. N. de. Formação inicial de professores para a educação básica: uma (re)visão radical. São Paulo em Perspectiva, São Paulo, v. 14, n. 1, p.98-110, 2000.

SAITO, F. Número e grandeza: discutindo sobre a noção de medida por meio de um instrumento matemático do século XVI. Ciências \& Educação, Bauru, São Paulo, v. 23, n. 4, p. 917-940, 2017.

SANTOS, A. A. dos. Engenharia didática sobre o estudo e ensino da fórmula de Binet como modelo de generalização e extensão da sequência de Fibonacci. 2017. 162 f. Dissertação (Mestrado em Ensino de Ciências e Matemática) - Programa de Pós-graduação em Ensino de Ciências e Matemática. Instituto Federal de Educação, Ciência e Tecnologia do Ceará (IFCE), Fortaleza, 2017.

SILVA, F. L. C. F. da. Analisando contribuições da teoria das situações didáticas no ensino e na aprendizagem da estatística e das probabilidades no ensino fundamental. 2015. $162 \mathrm{f}$.

Dissertação (Mestrado Profissional em Educação Matemática) - Programa de Pós-Graduação em Educação Matemática. Departamento de Matemática, Instituto de Ciências Exatas e Biológicas. Universidade Federal de Ouro Preto, Ouro Preto, 2015.

SOUZA, C. M. P.; LIMA, A. P. de A. B. O contrato didático a partir da aplicação de uma sequência didática para o ensino de Progressão Aritmética. Zetetiké, Campinas, São Paulo, v. 22, n. 42, p.155-168, 2014.

TEIXEIRA, P. J. M.; PASSOS, C. C. M. Um pouco da Teoria das Situações Didáticas (TSD) de Guy Brousseau. Zetetiké, Campinas, São Paulo, v. 21, n. 39, p.155-168, 2013. 